\title{
PRESENTACIÓN: \\ EXHUMACIONES DE FOSAS COMUNES Y MEMORIA \\ EN LA ESPAÑA ACTUAL
}

PRESENTATION:

EXHUMATIONS OF MASS GRAVES AND MEMORY

IN THE CURRENT SPAIN

Julián Chaves Palacios*

Universidad de Extremadura, Cáceres

* Correspondencia a: Julián Chaves Palacios. Universidad de Extremadura. Facultad de Filosofía y Letras. Departamento de Historia. Avenida de la Universidad s/n, Cáceres 10071 - jchapal@unex.es - https://orcid.org/0000-0001-6569-4750

Cómo citar: Chaves Palacios, Julián (2019). «Presentación: exhumaciones de fosas comunes y memoria en la España actual» Historia Contemporánea, 60, 395-400. (https://doi.org/10.1387/hc.20613.

ISSN 1130-2402 - eISSN 2340-0277 / (C) 2019 UPV/EHU 
Las exhumaciones de fosas comunes relacionadas con la represión franquista durante la guerra civil y régimen político posterior constituyen una realidad que está muy presente en la sociedad española del siglo XXI. Si bien fue a inicios de esa centuria cuando comenzaron esas intervenciones de forma regular por todo el país, sin embargo no cabe circunscribir estas actuaciones a tiempos recientes. Se tiene constancia que comenzaron a practicarse tras la muerte del dictador, extendiéndose a todo el período de la Transición política pese a las dificultades inherentes a esa etapa histórica, poco propicia para afrontar este tipo de iniciativas.

Pese a ello, bien a título particular, bien de forma colectiva, familiares con miembros enterrados en esas fosas decidieron proceder a su exhumación pese a no contar, en la mayoría de los casos, con la preceptiva autorización gubernativa. Atrevimiento, cuando no temeridad, por parte de las personas afectadas que no estaban dispuestas a aguantar por más tiempo el oprobio que suponía tener enterrados en una cuneta o descampado próximo a uno o varios miembros de su familia desde 1936. El sentimiento se imponía a la legalidad y no dudaron en afrontar esta empresa en el convencimiento de que era hora de hacer justicia y darle a los suyos un enterramiento digno después de tantos años soportando esa infamia.

Experiencia que sin embargo no tuvo sucesión de continuidad en los primeros años de democracia. Hasta finales de siglo asistimos a una ralentización cuando no práctica desaparición de las exhumaciones de fosas, ante la deriva política de los gobiernos socialistas de dejar en un segundo plano la historia y memoria de la contienda armada y régimen posterior y atender otras cuestiones consideradas más perentorias. La escasa legislación aprobada durante este período relacionada con las consecuencias sociales de la guerra civil y el franquismo demuestran de forma fehaciente el poco tiempo que dedicaron nuestros gobernantes a redimir cuentas relacionadas con ese pasado traumático.

Ha habido que esperar a los comienzos del presente siglo para apreciar un cambio sustancial al concurrir tanto iniciativas políticas y jurídicas como científicas y sociales. Las primeras han registrado un giro sin precedentes, con la aprobación de un corpus legislativo tanto estatal como autonómico que trata de dar cobertura legal a las demandas ciudadanas. Éstas se han visto acompañadas por un movimiento asociativo en representación de las víctimas que exigen verdad, justicia y reparación. Reivindicaciones que han fomentado la preceptiva investigación e intervención en fosas comunes, destacando en esa labor la conjunción de especialistas como forenses, arqueólogos e historiadores. 
Nuevo escenario que pese a los progresos conseguidos destaca por haber registrado significativos altibajos sobre todo en cuanto a decisiones políticas, al depender su impulso o ralentización, según las circunstancias, de la predisposición del Gobierno de turno a potenciarlas. La realidad, no obstante, es que todavía hay mucho trabajo por hacer, al existir aún fosas repartidas por el territorio hispano pendientes de intervenir. Tarea pendiente que pone de manifiesto la necesidad de abrir debates científicos desde diferentes campos de conocimiento que abunden en reflexiones que estimamos absolutamente necesarias para ajustar conceptos y planteamientos de futuro.

De ahí lo pertinente de este dossier que tiene como eje nuclear la exhumación de fosas comunes con restos de personas víctimas de las acciones represivas franquistas durante la contienda armada de 1936 y el régimen político posterior. Contenido que acapara buena parte de los debates que se suscitan alrededor de la denominada «memoria histórica» en la España actual. Se impone dar luz y taquígrafo no sólo a su problemática evolución sino también a su estado presente, siendo preciso dar a conocer los logros alcanzados pero también el trabajo por hacer para acabar de una vez por todas con este agujero negro de nuestra historia.

Sin duda su prolongación en el tiempo y la falta de una solución definitiva a este problema se ha convertido en una asignatura pendiente tanto para gobernantes como para gobernados, y entre éstos se encuentran los familiares afectados que exigen una solución concluyente a esta afrenta. Estamos convencidos que su subsanación cerrará una de las heridas más sangrantes de ese pasado traumático. Desde esa perspectiva y con el firme convencimiento de que es necesario dar respuesta a esta cuestión, hemos planteado los artículos que componen estas páginas, fruto de investigaciones desarrolladas por parte de reputados especialistas sobre esta temática.

$\mathrm{Y}$ en ese sentido es preciso señalar que no abundan en el campo historiográfico, del que es deudora la presente publicación, expertos que hayan abordado en sus indagaciones este tipo de contenidos. Si bien el concepto causante, la represión en sus diferentes modalidades, ha sido objeto de acreditados estudios, sin embargo las fosas comunes en sus distintas acepciones y consecuencias apenas han merecido interés. Se ha ignorado su relevancia, no solo en lo concerniente a su localización, intervención y resultados, sino también en el análisis de restos, no exclusivamente óseos, y su aportación al conocimiento histórico, como se puede constatar en las investigaciones que se ofrecen en estas páginas. 
Así, el antropólogo forense, Francisco Etxeberria, que junto a su grupo de trabajo de la Sociedad de Ciencias Aranzadi ha protagonizado con indudable éxito buena parte de las exhumaciones de fosas que desde inicios del presente siglo se han venido realizando en suelo español, comparte publicación con la historiadora y buena conocedora de esta materia, Queralt Solé. Ambos ofrecen un balance actualizado de estas intervenciones, incidiendo en la relevancia de la interdisciplinariedad en cuanto a su tratamiento.

Iniciativas que según los autores no se han visto acompañadas por la implicación oficial ni en el plano administrativo ni en el judicial. Incluso ese alejamiento gubernativo se ha podido constatar tras la controvertida aprobación de la conocida popularmente como Ley de Memoria Histórica, en 2007, que entre otras derivaciones ha destacado por registrar una demora de años en la puesta en funcionamiento de sus preceptivos reglamentos. Ralentización, no obstante, que se ha visto acompañada por la aprobación de una suerte de leyes y normativas autonómicas que han venido a cubrir las carencias de la ley estatal tanto en exhumaciones como en políticas públicas de memoria.

Por su parte, en la aportación individual a este dossier de la historiadora Queralt Solé, se lleva a cabo un ejercicio de aproximación a las distintas vertientes que presentan las producciones culturales e históricas ligadas a las fosas comunes. Y si bien las exhumaciones han tenido indudable repercusión social y han recabado la atención de diferentes disciplinas científicas, sin embargo esa importante presencia no se ha visto acompañada con igual fuerza en el mundo académico. Reticencias en cuanto a su aceptación desde el marco universitario que no han evitado la proliferación de obras desde otros ámbitos de incuestionable valor, que prueban la atención que han merecido estas intervenciones.

Así, desde inicios del presente siglo en que comienza este estudio, piezas escultóricas, instantáneas fotográficas, obras teatrales, composiciones musicales, esculturas, fotografías, documentales televisivos, exposiciones y, por supuesto, publicaciones han abordado el mundo de las fosas comunes. Ello ha contribuido no solo a dar respuesta a la demanda de familiares y cuerpos asociativos sino también a un mayor reconocimiento de este proceso. Contribuciones a las que también se ha incorporado la academia con algunas tesis doctorales y publicaciones diversas, aunque con cierto retraso y no de forma generalizada.

La arqueóloga Laura Muñoz, pionera en estas investigaciones en el mundo académico tras la defensa de su tesis doctoral sobre exhumacio- 
nes en la Universidad de Extremadura en el verano de 2016, que mereció la máxima calificación por parte del tribunal evaluador, plantea una novedosa propuesta de investigación y análisis de la represión basada en el estudio arqueológico y antropológico de las fosas comunes. Ésta tiene que estar acompañada de la preceptiva aportación documental y oral, de forma que la recuperación de los elementos materiales como los contextuales deben ser interrelacionados para poder obtener el máximo de información posible.

Con ese objetivo la metodología a emplear tiene una triple procedencia científica: historia, arqueología y antropología forense. Disciplinas que utilizadas conjuntamente permiten la reconstrucción de los hechos, el esclarecimiento de la verdad y la producción de conocimiento histórico del pasado traumático de la sociedad española representado en este caso por las exhumaciones de fosas. Proceso científico que en su opinión plantea la posibilidad de investigar la represión irregular franquista mediante el análisis de las fosas comunes.

Depósitos de cadáveres que ponen de manifiesto que desde inicios de la guerra civil las estrategias de eliminación representan el primer eslabón de la cadena del aparato represivo franquista, con personas ejecutadas sin pasar por ningún tipo de proceso judicial sobre las que apenas existe información documental. Su exhumación permite aclarar cuestiones como la ubicación del depósito, número de represaliados, tratamiento recibido, causa de muerte, uso de los cuerpos sin vida y modo de enterramiento de los cadáveres. Investigaciones que en no pocos casos posibilitan su identificación.

Y en lo concerniente al artículo del autor de estas líneas, sin abandonar esas cuestiones se profundiza en el corpus legislativo aprobado por los diferentes gobiernos de España desde la Transición política a la actualidad, destinado a resarcir a la ciudadanía afectada de las consecuencias de la guerra civil y dictadura posterior. Medidas reparadoras que se vieron fuertemente influenciadas por el contexto político y social vivido en España desde la muerte del dictador, pudiendo apreciar diferente evolución y comportamiento entre unas fases históricas y otras dependiendo, especialmente, de las circunstancias sociopolíticas imperantes.

Proceso que pone de manifiesto cómo el tiempo histórico influyó a la hora de legislar sobre ese pasado traumático, siendo desde inicios de la actual centuria cuando estas iniciativas han alcanzado mayor protagonismo. En ello influyeron factores como la generalización en toda España de las exhumaciones de fosas comunes a causa de la represión 
franquista, que se vieron acompañadas por las demandas de asociaciones y familiares de afectados que no han dudado en exigir respuesta a sus reivindicaciones.

Contexto que dio lugar al impulso de una legislación tanto en un plano nacional como autonómico sin precedentes en los años de democracia, que ha tenido como denominador común su aprobación en los respectivos parlamentos sin el necesario consenso por parte de las organizaciones políticas. Desacuerdo que no ha impedido su puesta en práctica, afectando a diferentes variables relacionadas con ese pasado entre las que destaca abordar sin dilación esta asignatura pendiente de nuestra historia que son las fosas comunes, aun presentes en nuestro territorio pese a que han transcurrido ochenta años desde la finalización de la guerra civil.

Por tanto, nos encontramos ante un contenido que trasciende el campo histórico, arqueológico y forense para situarse en el centro del debate de una parte significativa de la sociedad española que exige soluciones definitivas a este oprobio. Controversias y realidad que los diferentes autores del presente dossier hemos pretendido abordar desde parámetros científicos, convencidos de la obligación de dar a conocer desde presupuestos académicos no sólo el proceso histórico seguido en materia de exhumaciones de fosas comunes sino también el estado en que se encuentra esta cuestión en la actualidad. 